\title{
AB'NIN TEMEL DAYANAKLARININ PARÇASI OLARAK AZINLIKLARIN KORUNMASI
}

\author{
A.Füsun ARSAVA*
}

\section{$\ddot{O Z Z E T}$}

$A B$ anlaşmasinin 2.maddesi AB'nin istinat ettiği üye devletlerde ortak olan değerlerden biri olarak insan haklarına, azınlık haklarl dahil olmak üzere saygl gösterilmesinden söz etmektedir.

Makalede azınlık mensubu bireylerin haklarının somutlaştırılması bağlamında AB Temel Haklar Şartı'nın ve AB üyesi devletlerin taraf olduğu anlaşmaların rolü yanısıra, AB hukukunda azınlık haklarının korunmasında uygulanan yöntem, azınlık hakları korumasının AB'ne katılımda ve AB'nin diş ilişkilerinde oynadiğ rol ele alınmaktadır.

Anahtar Kelimeler: Azınlık kavramı, AB değerleri, AB Temel Haklar Şartı, Avrupa Konseyi bölgesel ve azınlık dilleri, Çerçeve Sözleşmesi, AGİT (Avrupa Güvenlik ve İsbirliği Teşkilatı) standardı

\section{THE PROTECTION OF MINORITIES AS A PART OF EUROPEAN UNION CORE PRINCIPLES}

\section{ABSTRACT}

Article 2 of the EU Treaty refers to respect for human rights including minority rights as one of European values common to the member states.

In this article, the roles of the EU Charter of Fundamental Rights and of the treaties to which EU member states are parties in the protection of individuals belonging to minorities are analyzed. And the method used in the protection of minority rights in EU law, the role of the protection of minority rights in the EU'S enlargement policy and in its foreign relations are also examined.

Key Words: concept of minority, EU values, EU Charter of Fundamental Rights, regional and minority languages of the Council of Europe, Framework Convention, OSCE standard

* Prof. Dr., Atılım Üniversitesi Hukuk Fakültesi Öğretim Üyesi (fusun.arsava@atilim.edu.tr)

Yayınlanmasının Uygun Görüldüğ̈̈ Tarih: 02/05/2019 


\section{A - Giriş}

Lizbon Sözleşmesinin 01.12.2009'da yürürlüğe girmesi ile AB azınlıkların korunması alanında yeni bir sayfa açmıştır. AB anlaşmasının 2.maddesi yanlış anlamaya imkan bırakmayacak şekilde AB'nin istinat ettiği üye devletlerde ortak olan değerlerden biri olarak çoğulculuk, ayrımcılık yasağı ve hoşgörü yanısıra insan haklarına azınlık hakları dahil olmak üzere sayg1 gösterilmesinden söz etmektedir. Lizbon Sözleşmesi’ne göre primer hukuk hiyerarşisine sahip olan Temel Haklar Şartı'nın 21.madde, 1.fikrası (AB anlaşması madde 6, fikra 1) kişilere ulusal azınlığa mensubiyetleri nedeniyle ayrımcılık yapılmasını yasaklamaktadır. Her iki hükmün de yenilik taşımadığ1, şimdiye dek mevcut olan düzenlemeleri teyit ettiği doğrudur ${ }^{1}$. Ancak şimdiye dek Avrupa entegrasyon tarihinde ilk kez AB primer hukukunda açık bir şekilde azınlıklara atıf yapılmıştır. Yapılan bu atıf AB'nin kapsamlı bir azınlık politikası kabul ettiği sonucu çıkarılmasa da, bu düzenlemelerin üye devletlerde azınlıklarla ilgili mevcut politikaların geliştirilmesine katkı sağlayacağı kesindir ${ }^{2}$. AB'de geçerli olacak azınlık hakları standardı ve kimlerin azınlık mensubu olarak kabul edileceği belirlenmeden Lizbon Sözleşmesinde AB'de azınlıkların korunmasının bir anayasa prensibi olarak açıkça tanınması eleştiri konusu olmaktadır³.

\section{B - Tarihi Nedenler}

Azınlıkların korunması sorunu oldukça geç, normatif olarak dolaylı şekilde Avrupa entegrasyonunun konusu olmuştur. Azınlıkların korunması 90'lı yılların başına kadar Avrupa Parlamentosu'nun azınlıkların korunmasına ilişkin gayretleri dışında o zamanki AET'nin gündeminde olan bir konu değildir" Sovyetler Birliği'nin ve Yugoslavya'nın dağılması ertesinde Avrupa'nın doğu ve güneyinde yaşanmaya başlanan etnik-ulusal uyuşmazlıklar Avrupa Topluluğu'nun ve üye devletlerin azınlıkların korunması konusuna

1 Frank HOFFMEISTER, "Grundlagen und Vorgaben für den Schutz der Minderheiten im EU-Primärrecht”, ZaöRV (Zeitschrift für ausländisches öffentliches Recht und Völkerrecht), Bd. 68, 2008, s. 175

2 Maximillian OPITZ, Die Minderheitenpolitik der Europäischen Union, Lit Verlag, Münster, 2007

3 AB Parlamentosunun bu çerçevedeki eleştirileri için bknz.: ABl.C-124 E, 25.5.2006, 405 (Amtsblatt der Europäischen Gemenschaften)

4 Peter HILPOLD, "Minderheiten im Recht der Europäischen Union”, Zur Entstehung des modernen Minderheitenschutzes in Europa, Christoph PAN,/Beate SYBILLE (ed.), Springer Verlag, New York, 2006, s.487 
şimdiye dek olduğundan daha fazla şekilde yoğunlaşmasına yol açmıştır 5 .

Takip eden gelişmelerde konu AT/AB'nin eski komünist devletlerin halefi devletlerle ilişkilerinde yer almaya başlamıştır. Topluluğun 1992'den itibaren ulusal azınlıkların haklarına saygıyı ilgili devletlerle yaptığı işbirliği anlaşmalarında vurgulamaya başlaması ve ünlü Kopenhag kriterlerinin 1993'te Avrupa Birliği tarafından kabulü ile birlikte azınlıkların korunması AB'nin genişleme politikasının önemli bir kriteri haline gelmiştir. AB ilk olarak Arnavutluk ve Baltık devletleriyle yaptığ ticaret ve işbirliği anlaşmalarında ulusal azınlık haklarının korunması vurgusunu yapmıştır. Bu uygulama doğu Avrupa ülkeleriyle yapılan işbirliği ve ortaklık anlaşmalarında devam ettirilmiştir ${ }^{6}$. Demokrasi, hukukun üstünlüğü, azınlıkların korunması dahil olmak üzere insan haklarına saygıyı temin eden istikrarlı kurumsal yapı bu şekilde AB'ne tam üyeliğin ön koşulu haline gelmiştir?.

Benzer şekilde bir süre sonra batı Balkan ülkeleri için Konsey tarafından ihdas edilen koşulluluk direktifinde de azınlıkların korunması bağlamında uluslararası seviyede tanınan standardın sağlanması, AB'nin mali ve teknik yardımının, aynı şekilde anlaşma ile doğan ilişkilerin sürdürülebilirliğinin ön koşulu olarak öngörülmüştür8. İlk etapta Doğu Avrupa ülkeleriyle ilişkilerde gündeme gelen azınlıkların korunması konusunun zaman içinde bir Birlik politikasının oluşmasına yol açtığı görülmektedir. AB'nin bu şekilde üçüncü devletlerle ilişkilerinde katı bir şekilde öngördüğü azınlık haklarının korunması kriterinin kendi iç ilişkilerinde de çifte standart eleştirilerini önlemeye matuf olarak telâfi edilmeye çalışıldığ 1 görülmektedir. AB Temel Haklar Şartı'nın hazırlandığı konvansiyon çalışmalarında kimi konvansiyon üyeleri tarafından kapsamlı bir azınlık hakları düzenlemesinin gereğine dikkat çekilmekle beraber Temel Haklar Şartı'nın nihai metninde bu yaklaşım benimsenmemiştir?.

Avrupa Konseyi 29.06.1991 tarihli insan haklarının korunmasına ilişkin deklarasyonunda Topluluğun bundan böyle üçüncü devletlerle ilişkilerinde gelecekte azınlıkların korunmasını daha çok dikkate alacağını ifade etmiştir. Bknz.: Bull.EG (Bulletin der Europäischen Gemeinschaften) 6-1991, Ziff.I.45

6 AT ve üye devletlerin Arnavutluk'la yaptığ ${ }_{1}$ istikrar ve ortaklık anlaşmasının dibacesinin 4.paragrafi için bknz.: AB1. L 107, 28.04.2009, 166

7 21/22.06.1993 tarihli Kopenhag kriterleri için bknz.: Bull.EG 6-1993, Ziff.I.13

$8 \quad$ bknz.: EU 4-1977,Ziff. 2.2.1

9 Sven HÖLSCHEIDT, “Artikel 22: Vielfalt der Kulturen, Religionen und Sprache”, Charta der Grundrechte der Europäischen Union, Jürgen Meyer (ed.) 3.bas1, Helbing \& Lichtenhahn Verlag, Basel, 2011, Rn.8ff (Randnummer) 
Ekim 2004'te imzalanan AB anayasa tasarısının I-2.maddesinde azınlık haklarının korunması ile ilgili hükmün açık bir şekilde yer almasına ilişkin inisiyatifin Kopenhag kriterleri 1şı̆̆ında AB'ne katılan Macaristan menşeli olması da şaşırtıc1 görülmemektedir ${ }^{10}$. AB anayasa tasarısının I-12.maddesi “AB'nin istinat ettiği değerleri "insan onuru, özgürlük, demokrasi, eşitlik, hukuk devleti ve azınlık hakları dahil olmak üzere insan hakları" olarak düzenlemiştir. Düzenlemenin devamında çoğulculuk, ayrımcılık yasağı, hoşgörü, adalet, dayanışma ve kadın-erkek eşitliği de $\mathrm{AB}$ değerleri olarak ifade edilmiştir.

\section{2.maddesi}

C - Değerler Topluluğunun Temel Normu Olarak AB Anlaşmasının

Bir anayasa anlaşması yapma projesinin gerçekleşmemesi ertesinde anayasa tasarısının I-2.maddesi içerik olarak herhangi bir değişikliğe uğramadan Lizbon Sözleşmesinin 2.maddesi tarafından üstlenilmiştir. $\mathrm{Bu}$ şekilde, şimdiye dek $\mathrm{AB}$ anlaşmasının 6.madde, 1.fikrasında insan haklarının korunması şeklinde düzenlenen hüküm primer hukukta azınlıklara mensup bireylerin hakları dahil olmak üzere insan haklarına saygı şeklinde düzenlenmiştir. Bireyselleştirilen azınlık koruması bu şekilde AB'nin değerlerine dahil olmuş ve Avrupa Birliği hukukunun temel normu olma özelliği kazanmıştır ${ }^{11}$. Bu değerlerin bağlayıcı olduğu sadece AB'nin istinat ettiği değerleri öngören $\mathrm{AB}$ anlaşmasının 2.maddesinden değil, bu değerlerin AB'nin kimliğinin bir özelliği olarak geliştirilmesini öngören anlaşma hükümlerinden de istihraç edilmektedir. Diğer bir ifade ile $\mathrm{AB}$ anlaşmasının 2.maddesinin sadece $\mathrm{AB}$ organlarının anlaşmada öngörülen yetkilerini kullanırken esas aldıkları yetki dayanağı olarak değil, aynı zamanda madde hükmünde öngörülen değerlerin yönlendirici prensipler olarak dikkate alınması ve onlara gerektiği gibi geçerlilik sağlanması yükümlülügü getiren hüküm olarak anlaşılması gerekmektedir. 2.madde, 2.fikraya göre söz konusu değerler tüm üye devletlerde ortaktır. Bu şekilde Birlik anlaşmasının değerlerle ilgili normu bu prensiplerle bağlı olan Birliğin kendisi gibi üye devletleri de (özellikle $\mathrm{AB}$ anlaşmasının 7.maddesi bağlamında) bağlamaktadır ${ }^{12}$.

10 HOFFMEISTER, s. 181

11 Francesco PALERMO, "Annäherungen and den "Verfassungsrecht der Europäischen Verfassungsraums", Vom Verfassungsstaat am Scheideweg, Karl WEBER, Norbert WIMMER (ed.), Springer, Vienna/New York, 2005, s.295

12 Roland BIEBER/Astrid EPINEY/Marcel HAAG, Die Europäische Union, 9.bası, Nomos Verlag, 2011, s.101 
$\mathrm{AB}$ anlaşmasının 2.maddesi iki fonksiyon yerine getirmektedir. Bunlardan birincisi kaynağ 1 itibariyle ulusal hukuk nitelikli prensiplerin supranasyonal seviyede anayasa prensibi kategorisine yükseltilerek avrupalılaştırılması, diğeri federal yahut federal devlet benzeri bir yapıya sahip AB' de "homojenlik kuralı" işlevi görmesidir. Diğer bir ifade ile AB anlaşmasının 2.maddesi bir taraftan vertikal (dikey) homojenlik prensibi olarak AB'nin anayasal değerleri ile üye devletlerin anayasalarına esas olan değerler arasında, diğer taraftan da horizontal (yatay) homojenlik kuralı olarak üye devletlerin anayasal yapıları arasında uyumluluğu dile getirmektedir ${ }^{13}$.

D - AB Anlaşmasının 2.madde 1.fikrasının Normatif İçeriğinin Belirlenmesi

$\mathrm{AB}$ değerlerine $\mathrm{AB}$ 'nin karakterine uygun bir içerik verilmesinde $\mathrm{AB}$ anlaşmasının 2.maddesinin işaret ettiği üzere bu değerlerin ulusal anayasa hukuku menşei esas olmaktadır. Bu değerlerin somutlaştırılmasında normlara ve prensiplere içerik kazandırılması bağlamında öncelikle üye devletlerin ortak anayasal geleneklerine istinat edilmektedir ${ }^{14}$. Azınlık haklarının korunmas1 konusunda ancak üye devletler arasında önemli farklılıklar görülmektedir. AB'nin istinat ettiği değer olarak ve üye devletlerin ortak anayasal değeri olarak ilan edilen azınlık haklarının normatif içeriğinin belirlenmesinde bu nedenle üye devletlerin uluslararası seviyede yaptıkları açıklamaların ve taahhütlerin dikkate alınması gerekmektedir.

\section{I - Normatif Lâfzın Esas Alınması}

$\mathrm{AB}$ anlaşmasının 2.maddesinden öncelikle $\mathrm{AB}$ 'nin istinat ettiği söz konusu temel değerin madde hükmünde bireysel bir hak olarak kabul edildiği ve bu nedenle münhasıran azınlık mensubu bireylerin haklarının korunmasına matuf olduğu, ulusal grup haklarının veya kolektif hakların düzenlenmediği istihraç edilmektedir ${ }^{15}$. $\mathrm{AB}$ anlaşmasının 2.madde hükmü

13 Frank SCHORKOPF, "Homogenität in der Europäischen Union - Ausgestaltung und Gewährleistung durch Art.6, Abs.1 und Art.7 EUV", Hamburger Studien zum Europäischen und Internationalen Recht, Bd. 21, Duncker \& Humblot, Berlin, 2000, s. 101

14 Christian CALLIESS, “Art.2 EUV”, EUV/AEUV (Der Vertrag über die Europäische Union/Vertrag über die Arbeitsweise der Europäischen Union): Das Verfassungsrecht der Europäischen Union - Kommentar, Matthias RUFFERT (ed.), 4.bas1, Beck Verlag, Münih/Frankfurt, 2011), Rn.14

15 Nicola WENZEL, Das Spannungsverhältnis zwischen Gruppenschutz und Individualschutz im Völker-recht, Springer Verlag, Berlin/ Heidelberg/New York, 2008, s.17vd. 
Temel Haklar Şartı'nın ulusal azınlıklarla ilgili 21.maddesinden farklı olarak genel bir kavram olarak azınlık kavramını kullanmaktadır. Temel değerlere ilişkin madde hükmünün lâfzı bu nedenle azınlık kavramının yeni azınlık mensuplarını da kapsar şekilde yorumunu gerektirmektedir ${ }^{16}$.

Bölgesel olarak Avrupa'da da genel olarak kabul gören bir azınlık tanımının bulunmadığının ve özellikle Avrupa Konseyi’nin ve AGIT'in ilgili dokümanlarının devletlerin çoğu tarafından yeni azınlıkları kapsar şekilde yorumlanmadığının ve uygulanmadığının gözardı edilmemesi gerekmektedir. Buna karşıllı uluslararası seviyede artan şekilde ikâmet edilen devletin vatandaşı olma kriterinin bir kişinin ulusal azınlık mensubu olarak mütalâa edilmesinde önemini kaybettiği görülmektedir. Bundan bağımsız olarak temel değerlere ilişkin hükümde azınlık korumasının insan hakları korumasının bir boyutu olarak vurgulanması, bu hükmün sadece herkese verilen hak ve özgürlüklerin ayrımcılık yapmadan azınlık mensupları için de temin edilmesi ile sınırlı olmayıp, daha çok azınlık mensupları için özel hakların teminine matuf olarak düzenlendiğini göstermektedir ${ }^{17}$.

\section{II - AB Temel Haklar Şartı ve AİHK İlişkisi}

AB Adalet Divanı 1970'li yıllardan itibaren temel hakları üye devletlerin ortak anayasal geleneklerinden ve özellikle AİHK'dan doğan hali ile Birlik primer hukukunda geçerli genel hukuk ilkeleri olarak nitelendirmektedir. AB AdaletDivanı'nın sürekliiçtihatınagöreinsanhaklarınasaygı-ABanlaşmasının 2.maddesine göre azınlık haklarını da kapsar şekilde- $A B$ organlarının tasarruflarının hukuka uygunluğunun ve $\mathrm{AB}$ hukukunun uygulanma alanında ihdas edilen üye devlet tasarruflarının hukuka uygunluğunun önkoşuludur. İnsan haklarına aykırı olan önlemlerin $\mathrm{AB}$ hukukuna uygun mütalâa edilmesi mümkün değildir ${ }^{18}$. AB Adalet Divanı temel haklarla ilgili içtihatında şimdiye dek azınlıklara mensup bireylerin somut hakları bağlamında sadece açık bir

16 Geleneksel yaklaşıma göre ulusal azınlıklar kavramından kuşaklardan beri belli bir devletin egemenlik alanında doğan, yaşayan ve bu devletin vatandaşı olan etnik, kültürel, dini yahut dil azınlıkları anlaşılmaktadır. Yeni azınlıklar kavramı ise buna karşılık ağırlıklı olarak o ülkede doğmayan göçmen azınlıkları ifade etmektedir; bknz: Peter HILPOLD, "Neue Minderheiten im Völkerrecht und im Europarecht”, AVR, Bd.42, Say1 1, 2004, s.80

17 Waldemar HUMMER, "Minderheitenschutz im Recht der EU vor und nach dem Inkrafttreten des Vertrages von Lissabon. Vom bloßen Diskriminierungsverbot zu 'affirmative actions "', EJM (Euopäisches Journal für Minderheitenfragen) , No.2, 2011, s.81

18 AB Adalet Divanı'nın 2/94 sayıl1, 28.03.1996 tarihli danışma görüşü için bknz.: Slg.1996, I-17/63, Rn.34; AB Adalet Divan1, Kadi und Al Barakaat davas1, karar 03.09.2008, Rs. C-402/05 P ve C-415/05 P,Slg.2008, I-6351, Rn.281 vd. 
şekilde Birlik hukuku genel ilkelerine gönderme yapmamış, aynı zamanda azınlıkların korunmasını $\mathrm{AB}$ hukukunun gereği olarak ulusal politikaların meşru hedefi olarak kabul etmiştir ${ }^{19}$.

AB Adalet Divanı içtihatında azınlık haklarının korunması prensibinin maddi içeriğine ilişkin daha kapsamlı bir ipucu bulunmamasına rağmen negatif azınlık korumasının (ayrımcılık yapılmaması) AB müktesebatının doğal parçası olduğu konusunda bir tereddüt bulunmamaktadır. AB Temel Haklar Şartı yargıcın hukuk yaratma yöntemi ile yazısız hukuk olarak uygulanan AB temel haklarını somutlaştırmıştır. Temel Haklar Şartı'nın 21.maddesi ulusal bir azınlığa mensubiyet nedeniyle ayrımcılığı yasaklamış ve gerek AB organlarını ve kurumlarını, gerekse üye devletleri ${ }^{20}$ bu yasağın gereğini yerine getirmekle mükellef kılmıştır. Doğrudan uygulanma özelliğine sahip olan bu normun somutlaştırılması AB Adalet Divanı'na saklı tutulmuştur. AB Adalet Divanı bu çerçevede ulusal azınlık kavramının ne ölçüde dar yorumlanacağını, diğer bir ifade ile ulusal azınlık kavramının vatandaşlık bağına istinat ettirilip ettirilmeyeceğini açıklığa kavuşturma yetkisine sahiptir ${ }^{21}$. AB, AB Temel Haklar Şartı'nın ayrımcılık yasağı öngören 21.maddesi yanısıra AB'ni kültür, din ve dil çeşitliliğine saygı göstermekle yükümlü kılan 22.maddesi ile de yükümlülük altına sokulmuştur. Temel Haklar Şartı'nın 22.maddesi Avrupa Birliği'ni sadece münferit üye devletler tarafından temsil edilen çeşitliliğe sayg1 göstermekle değil, üye devletlerde mevcut kültür, din ve dil çeşitliliğine saygı göstermekle de yükümlü kılmıştır. Bu norm AB Temel Haklar Şartı'nın 52.madde, 5.fikrası muvacehesinde temel bir norm teşkil etmektedir. $\mathrm{Bu}$ nedenle ulusal azınlığa mensup bireylerin sübjektif hakları ellerinden alınamaz. AB Temel Haklar Şartı'nın 22.maddesi objektif hukuk nitelikli bir düzenleme olarak $\mathrm{AB}$ organlarına anlaşmalarda öngörülen yetkilerini kullanmaları bağlamında alacakları kararlar için kriter öngörmektedir.

Madde hükmünde bunun ötesine giden çeşitliliği koruma yahut desteklemekle ilgili özel bir yükümlülük kabul edilmemiştir. AB'nin istinat ettiği temel bir değer olarak azınlık korumasının somut içeriğinin belirlenmesinde ortak anayasal gelenekler yanısıra, AB Adalet Divanı

19 AB Adalet Divanı, Bickel und Franz, 24.11.1998 tarihli karar için bknz.: Rs. C-274/96, Slg.1998, I-7637, Rn.29; Roman Angonese/Cassa di Risparmio di Bolzano SpA, 06.06.2000 tarihli karar için bknz.: Rs.C-281/98, Slg.2000 I-4139, Rn.44

20 Temel Haklar Şartı'nın 51.madde, 1.fikrası muvacehesinde üye devletler sadece AB hukukunun icrası bağlamında yükümlülük altına sokulmuştur

${ }^{21}$ HILPOLD, s.103 
tarafindan temel haklar alanında yargıcın hukuk yaratması bağlamında birincil kaynak olarak işaret edilen AİHK'nu da büyük ölçüde önem taşımaktadır. AİHK'nun 14.maddesi de ulusal bir azınlığa mensubiyet nedeniyle ayrımcılık yapılmasını yasaklamaktadır. 14.maddenin koruma standardının madde hükmünde genel bir ayrımcılık yasağı öngörmek yerine sadece Konvansiyonda öngörülen hakların kullanılması bağlamında ayrımcılığın yasaklanması nedeniyle AB Temel Haklar Şartı'nın gerisinde kaldığ kabul edilmektedir $^{22}$. AİHM içtihatında kimi konvansiyon haklarının (örgütlenme, düşünce ve inanç özgürlügü, özel ve aile yaşamı) potansiyel azınlık hakları boyutuna dikkat çekmiş ve konvansiyonla uyumlu yegane siyasi model olarak çoğulcu demokrasi prensibine atıf yapmıştır' ${ }^{23}$ AB Adalet Divanı'nın temel haklar standardının arada geçen süre içinde büyük ölçüde AİHK standardı ile uyum sağlaması paralelinde Strazburg Mahkemesi içtihadının AB'de temel hak korumasında önem kazandığ 1 görülmektedir ${ }^{24}$. Bununla beraber AİHK'nun (AB Temel Haklar Şartı bakımından da söz konusu olduğu üzere) azınlıklar için özel temel haklar öngörmediğinin ve bu nedenle azınlık mensubu bireylerin kimliklerinin korunmasına matuf pozitif koruma önlemlerinin alınmasına ilişkin hak iddia etme olanağına sahip olmadıklarının göz ardı edilmemesi gerekmektedir.

III - Ulusal Azınlıkların Korunmasına İlişkin Avrupa Konseyi Çerçeve Sözleşmesi

Ulusal azınlık mensubu bireyler için özel haklar öngören şu an için 39 Avrupa Konseyi üyesini taahhüt altına sokan sözleşmenin ${ }^{25} \mathrm{AB}$ anlaşmasının 2.maddesinde yer alan azınlık mensubu bireylerin haklarını korunmasına ilişkin Avrupa Birliği'nin istinat ettiği değerlerin yorumunda dayanak olarak alınması sorunlu gözükmektedir. Bunun en önemli nedeni beş $A B$ üyesi

22 Genel ayrımcılık yasağı AİHK'na ek 12 nolu protokolle kabul edilmiştir. Protokol şimdiye dek 7'si AB üyesi olan 18 devlet tarafindan onaylanmıştır

23 AİHM, Baczkowski-Polonya, karar 03.05.2007, Nr.1543/06, Rn.63; Wolfram KARL, "Der Schutz der Minderheitenrechte im Rahmen des Europarats", Schutz und Durchsetzung der Rechte nationaler Minderheiten, Gerhard HAFNER/Martin PANDEL (ed.), Nomos, Baden-Baden, 2008, s.79

24 Eckart KLEIN, "Das Verhältnis des EuGH zum EGMR", Handbuch der Grundrechte VI/1: Europäische Grundrechte I, Detlef MERTEN/Hans-Jürgen PAPIER (ed.), Mohr Siebeck, Heidelberg, 2010, §167

25 Sözleşme 01.02.1998'de yürürlüğe girmiştir. Avrupa Konseyi'nin azınlıkların korunmasıyla ilgili olan diğer sözleşmesi 05.11.1992 yürürlüğe giren Bölgesel ve Azınlık Dilleri Avrupa Şartı şimdiye dek 16'sı AB üyesi olan 25 Avrupa Konseyi üyesi tarafından onaylanmıştır 
devletin sözleşmeyi henüz onaylamamış olmasıdır ${ }^{26}$. AB Adalet Divanı da temel haklarla ilgili içtihatında şimdiye dek bölgesel ve azınlık dilleri Şartı'na atıf yapmamıştır. Bununla beraber AB Adalet Divanı'nın içtihatında ortaya koyduğu temel haklarla ilgili yaklaşım bu sözleşmenin $\mathrm{AB}$ temel hakları bağlamında dikkate alındığını göstermektedir. Birlik temel haklarının nitelendirilmesi ve yorumunda AB Adalet Divanı üye devletlerin ortak anayasal gelenekleri dışında insan haklarının korunması alanında $\mathrm{AB}$ üyesi devletlerin taraf olduğu yahut katıldığı uluslararası anlaşmaları da esas almaktadır ${ }^{27}$. Literatürde temsil edilen kimi görüşlere göre $\mathrm{AB}$ Adalet Divanı'nın bu yaklaşımının sözleşmenin müzakerelerine tüm $\mathrm{AB}$ üyesi devletlerin katılmış olması ve Fransa dışında tüm AB üyesi devletlerin imzalamış olması nedeniyle Bölgesel ve azınlık dilleri sözleşmesine de uygulanması mümkündür ${ }^{28}$. Nold davasının İngilizce kaleme alınan metninde "treaties on which member states have collaborated or to which they are signatories" șeklinde yer alan ifade Adalet Divanı'nın AB temel haklarının yorumu bağlamında zorunlu şekilde uluslararası anlaşmaların onaylanmış olmasından hareket etmediğini göstermektedir ${ }^{29}$.

AB Adalet Divanı'nın içtihatında Avrupa Konseyi çerçeve sözleşmesine ne ölçüde yer verdiği sorusunun cevabından bağımsız olarak AB'nin diğer organlarının kendi yetkilerini kullanırken $\mathrm{AB}$ değerlerinin temini ve geliştirilmesi bağlamında çerçeve sözleşmeye ne ölçüde istinat ettiği hususunun da değerlendirilmesi önemlidir; örneğin Parlamento Haziran 2005 tarihli Komisyona azınlıkların korunmasına ilişkin olarak yaptığ1 çağrıda ulusal azınlıkların, ulusal azınlıklar çerçeve sözleşmesinin 4.madde, 2.fikrasının esas alınarak korunması gereğinin altını çizmiştir ${ }^{30}$. Konvansiyon ulusal azınlık mensuplarına somut, bireysel olarak korunmasını talep edebilecekleri haklar tanımamıştır. Konvansiyon, devletlerin iki taraflı, çok taraflı anlaşmalarla yahut ulusal yasama tasarrufları veya siyasi tasarrufları ile

\footnotetext{
26 Belçika, Hollanda, Lüksemburg ve Yunanistan sözleşmeyi imzalamış olmakla beraber henüz onaylamamıştır. Fransa ise sözleşmeyi imzalamaktan imtina etmektedir

27 AB Adalet Divanı Nold-Komisyon davasında verdiği 14.05.1974 tarihli kararı için bknz.: Rs. 4/73, Slg.1974, 491, Rn.13

28 Kirsten SHORAKA, Human Rights and Minority Rights in the European Union, Taylor and Francis Group,London/New York, 2000, s.148

29 Roland WINKLER, Die Grundrechte der Europäischen Union, Springer Verlag, Wien/ New York, 2006, s.73

30 AB1. C 124 E, 25.05.2006, 405, §6
} 
gerçekleştirilecekleri genel hedefler öngörmüştür ${ }^{31}$. Sözleşme bunun dişında ulusal azınlıkların tanımını yapmamaktadır; kolektif hakların verilmesi bütünüyle devletlerin takdirine bırakılmıştır. Çerçeve sözleşmenin bununla beraber Avrupa'da azınlıkların korunmasında taşıdığı önemin inkâr edilmesi mümkün değildir.

\section{IV - Azınlıkların Korunmasında AGITT Standardı}

$\mathrm{AB}$ anlaşmasının 2.maddesinde $\mathrm{AB}$ 'nin istinat ettiği temel değerler arasında yer alan azınlıkların korunmasına ilişkin hükmün somutlaştırılması bağlamında Avrupa Güvenlik ve İşbirliği teşkilatının standardı da dikkate alınmaktadır. AB'nin tüm üyeleri aynı zamanda AGIT'in de üyeleridir; AGİT bünyesinde insan hakları ile ilgili olarak kabul edilen tüm belgeler, o zamanki adı ile AT üyesi devletlerin de dahil oldukları prosedürlerle oybirliği ile karara bağlanmıştır ${ }^{32}$. AGİT bünyesinde kabul edilen yükümlülükler sadece siyasi nitelikli olup, hukuken doğrudan bağlayıcı karakterde değildir. Bununla beraber kabul edilen bu metinler bu özellikleri dikkate alınmaksızın Avrupa kamu düzeninin ayrılmaz bir parçası olarak mütalâa edilmektedir ${ }^{33}$. AİHM bu nedenle tereddütsüz şekilde içtihatında AİHK'nun azınlık mensuplarının hakları ile bağlantılı olarak 1990 tarihli AGIT Kopenhag belgesine gönderme yapmıştır ${ }^{34}$.

Avrupa Konseyi'nin yaklaşımı paralelinde AGIT bünyesinde de azınlıkların korunması bağlamında açık şekilde ulusal azınlıklar esas alınmaktadır. Yeni bir Avrupa için Paris Şartı'nda ulusal azınlıkların etnik, kültür, dil ve din kimliklerinin korunması katılımcı devletler tarafindan azınlık mensuplarının bu çerçevede sahip olacakları haklar spesifik olarak dile getirilmeksizin ortak prensip olarak ilan edilmiştir. Bu durum 1990 tarihli insani boyut konferansı sonunda kabul edilen Kopenhag belgesine bireysel hakların

31 Konvansiyon hükümlerinin kural olarak tanıdığı takdir hakkı ile ilgili olarak bknz.: Karl, Wolfram. Schutz der Minderheiten im Rahmen des Europarats, bknz.: Hafner, Gerhard/Pandel, Manfred (Hrsg.). Schutz und Durchsetzung der Rechte nationaler Minderheiten (2008), 85

32 AGİT'in insani boyut konferansı sonunda kabul ettiği 29.06.1990 tarihli AGITT Kopenhag dokümanı, 19.11.1990 tarihli yeni bir Avrupa için Paris Şartı için bknz.: (http//www.osce. org/me/39516 (1.3.2012)

33 Christiane HÖHN, Zwischen Menschenrechten und Konfliktprävention: Der Minderheiten-schutz im Rahmen der Organisation für Sicherheit und Zusammenarbeit in Europa (OSZE), Sprringer Verlag, Berlin/Heidelberg, 2005, s.205 vd.

34 AİHM'nin Sidiropoulos-Yunanistan davasında verdiği 10.07.1998 tarihli karar için bknz.: Nr.26695, Rn.41,44 
korunması yaklaşımının esas alındığını göstermektedir. Avrupa Konseyi’nin ulusal azınlıklar çerçeve sözleşmesinin şekillendirilmesine dayanak teşkil eden Kopenhag belgesinin bütünü itibariyle katılımc1 devletlerin gerektiği takdirde azınlık mensuplarının eşitliğini temin etmek için pozitif önlemler alabileceğini dile getiren ifadesi azınlıkların korunmasında negatif haklar yaklaşımının aşıldığını göstermektedir. Ulusal azınlık mensubu bireyler için tanınacak özel haklarla bağlantılı olarak AGİT ulusal azınlıklar yüksek komiserliği periyodik olmayan şekilde üye devletlere yükümlülükleriyle ilgili olarak tavsiyeler ve direktifler ilan etmektedir ${ }^{35}$.

\section{V - BM Medeni ve Siyasi Haklar Sözleşmesi}

$\mathrm{AB}$ Adalet Divanı'nın $\mathrm{AB}$ değerlerinin normatif içeriğinin tespiti bağlamında içtihatında insan haklarının korunmasına ilişkin uluslararası hukuk enstrümanı olarak bütün $\mathrm{AB}$ üyesi devletlerin taraf olduğu BM Medeni ve Siyasi Haklar Sözleşmesi'ne de yer verdiği görülmektedir ${ }^{36}$. BM Medeni ve Siyasi Haklar Sözleşmesi'nin 27.maddesi taraf devletlere etnik, dini yahut dil azınlıkları mensuplarının, gruplarının diğer mensuplarıyla birlikte kültürlerini, inançlarını din ve/veya dillerini geliştirme, icra etme haklarından mahrum etmeme mükellefiyeti getirmektedir. Engellememe yaklaşımı ile düzenlenen 27.madde hükmü evrensel azınlık koruması alanında öngördüğü asgari standart nedeniyle Avrupa Konseyi ve AGIT standardının gerisinde kalmaktadır. 27.madde ulusal azınlıklarla sınırlı bir düzenleme öngörmediği gibi ikâmet edilen ülke devletinin vatandaşlığını da madde hükmünde öngörülen haklardan yararlanmak için önkoşul olarak kabul etmemiştir. Madde hükmünün bununla beraber pozitif azınlık koruması bakımından tatmin edici olmadığ açıktır. Sözleşmeyi yorumlama yetkisine sahip olan insan hakları komitesinin görüşüne göre taraf devletler azınlık mensuplarını azınlık haklarından mahrum edilmeyi önleyen gerekli önlemleri almakla mükelleftir. BM insan hakları komitesi bu bağlamda azınlıkların kimliklerini koruması ve mensuplarının haklarının korunması için destekleyici önlemlerin alınmasının gerekli olabileceğine sadece bir işaret yapmıştır ${ }^{37}$. Üye devletlerin

35 şimdiye dek bağımsız uzmanlar tarafından hazırlanan altı tavsiyenin ilan edildiği görülmektedir; bknz.: (http//www.osce.org/hcnm/66209(1.3.2012)

36 Fransa'nın BM Medeni ve Siyasi Haklar Sözleşmesi'nin azınlıkların korunmasına ilişkin 27.madde ile ilgili çekincesi AB'nin istinat ettiği temel değerlerin normatif içeriğinin tespiti amaçlı BM Medeni ve Siyasi Haklar Sözleşmesine gönderme yapılması nedeniyle önem taşımamaktadır

37 United Nations Human Rights Committee, General Comment No.23: The Rights of Minorities (Art.27), CCPR/C/21/rev.I/Add5(08.04.1994), 2.5.2 
bu bağlamda somut bir yükümlülüğünün bulunduğu sözleşmeden istihraç edilmemektedir.

E - AB Anlaşmasının 2.madde, 1.cümlesinin AB Primer Hukukundaki Yeri

AB'nin istinat ettiği değerlerden biri olarak azınlık mensubu bireylerin haklarına saygı, AB anlaşmasının 3.maddesinde öngörülen amaçlar muvacehesinde bu hakların geliştirilmesi mükellefiyetini de beraberinde getirmektedir. Aynı şekilde AB anlaşmasının 13.madde 1.fikrası Birlik organlarına bu değere geçerlilik sağlama mükellefiyeti getirmiştir. Her iki yükümlülüğün yerine getirilmesi de anlaşmalarda öngörülen yetkilerin kullanılması bağlamında söz konusu olmaktadır. $\mathrm{Bu}$ çerçevede $\mathrm{AB}$ anlaşmasının hiçbir hükmünün $\mathrm{AB}$ organlarına azınlıkların korunması konusunda düzenleme yapma veya uluslararası anlaşmalar akdetme yetkisi vermediğinin gözardı edilmemesi gerekmektedir ${ }^{38}$. Bu nedenle AB'nin çalışma usulleri hakkındaki anlaşmanın 10.maddesinde ve 19.madde, 1.fikrasında ayrımcılıkla mücadele bağlamında yapılan özel yetkilendirme bir istisna teşkil etmektedir.

Ulusal azınlığa mensubiyet nedeniyle yapılan ayrımcılıkla mücadeleye matuf önlemlerin bu hükümlere istinaden alınması prensip olarak caiz değildir ${ }^{39}$. Konsey şimdiye dek (AT anlaşmasının AB'nin çalışma usulleri hakkındaki anlaşmanın 19.maddesi) ırk yahut etnik köken ayrımı yapılmadan eşit muamele yapılmasına ilişkin bir direktifi (ABl. L180, 19.07.2000, 22) ve istihdam ve meslek icrasında eşit muamele yapılması ile ilgili genel çerçeve belirleyen 78/2000sayılı direktifi (AB1. L 303, 02.12.2000, 16) ihdas etmiştir. Komisyonun inanç yahut dünya görüşü, engellilik, yaş yahut cinsel tercih nedeniyle ayrımcılığ Bunun dışında primer hukukta sosyal dışlanma ile mücadele, dil ve kültür çeşitliliğinin teşviki, bölgesel teşvik, göç politikası alanlarında yer alan yetki normlarına azınlıkların korunması bağlamında dolaylı olarak istinat edilmesi mümkündür. Ancak bu tablo AB'nin ikincil hukuk araçlarıyla kapsamlı bir azınlık politikasının şekillendirilmesi olanağını tanıdığı sonucunu

38 AB Adalet Divanı'nın Bickel ve Franz davasında verdiği 24.11.1998 tarihli karar için bknz.: Rs. C-274/96, Slg.1998, I-7637, Rn.29; AB Adalet Divanı'nın Angonese davasında verdiği 06.06.2000 tarihli karar için bknz.: Rs. C-281/98, Slg.2000, I-4139, Rn.44

39 Oliver de SCHUTTER, Die Anerkenung der Rechte von Minderheiten und die Gleichbehandlungs-agenda der EU, Europäische Zeitschrift zum Antidiskriminierungsrecht \#11-2010, s.25 
doğurmamaktadır. Bu çerçevede Birliğe belli koşullar altında şekli anlaşma değişikliği dışında muhtar olarak yetki oluşturma olanağı veren AB'nin çalışma usulleri hakkındaki anlaşmanın 352 maddesi (eski AT anlaşmasının 308.maddesi) işlevsel bir önem taşımaktadır. Söz konusu hükme göre Konsey anlaşmalarda öngörülen politika alanları itibariyle anlaşmalarda yer alan amaçları gerçekleştirmek için anlaşmalarda gerekli yetkilerin öngörülmemesi halinde uygun önlemleri ihdas etme yetkisine sahiptir. Lizbon anlaşması ile getirilen değişikliklerden itibaren bu hüküm genel bir amaç olan Birlik değerlerinin desteklenmesi bağlamında bu değerlerden biri olan azınlık mensubu bireylerin haklarının korunmasına matuf olarak kullanılabilecektir.

AB'nin yetkilerinin AB'nin çalışma usulleri hakkındaki anlaşmanın 352. maddesine istinaden azınlıkların korunması alanına genişletilmesi olanağına şüphesiz anlaşmalarda saptanan politika alanları üzerinden sınırlama getirilmiştir ${ }^{40}$. Anlaşmaların kapsamına giren alanlarda azınlık mensuplarının gereksinimlerinin sınırlı şekilde karşılanması $\mathrm{AB}$ tarafından caiz kabul edilirken, AB'nin çalışma usulleri hakkındaki anlaşmanın tamamlayıcı şekilde yetkileri genişletilen 352.maddesine (gerekli gözükse de) bu çerçevede istinat edilmesi tereddüt yaratmaktadır. Bu tür kararların Konsey'de ancak oybirliği ile alınabilmesi de ayrı bir sorun teşkil etmektedir.

\section{II - AB Değerlerinin Horizontal (yatay) Homojenliğinin Temini}

$\mathrm{AB}$ anlaşmasının 2.madde, 2.cümlesi $\mathrm{AB}$ değerlerinin tüm üye devletlerin anayasal yapılarında herhangi bir şekilde yansıması gerekliliğine işaret etmektedir. Söz konusu bu yatay homojenlik gereğinin temini için AB anlaşmasının 7.maddesi azınlık mensubu bireylerin haklarının bir üye devlet tarafindan ağır ihlâli veya ihlâl tehdidi durumunda uygulanması mümkün bir yaptırım mekanizması öngörmektedir. $\mathrm{AB}$ anlaşmasının 7.maddesi $\mathrm{AB}$ değerlerinin sadece $\mathrm{AB}$ hukukunun üye devletler tarafından icrası bağlamında ihlâli durumunu değil, üye devletlerin bu değerlerin $\mathrm{AB}$ hukuku ile bağlantısı olmayan bir bağlamda ihlâli durumunu da düzenlemektedir ${ }^{41}$.

Lizbon sözleşmesinde çok sınırlı değişikliğe (şekilde değişiklik) uğrayan 7.maddede öngörülen prosedür Komisyon, Parlamento yahut 1/3 üye devlet tarafından işletilebilmektedir. Bir erken uyarı süreci ertesinde Konsey’in

\footnotetext{
40 Matthias ROSSI, “Art.352 AEUV”, EUV/AEUV: Das Verfassungsrecht der Europäischen Union - Kommentar, Christian CALLIESS /ManfredRUFFERT (ed.), 4.bas1, 2011, Rn.37 vd.

41 Manfred RUFFERT, Rn.4
} 
nitelikli çoğunlukla aldığı karara istinaden ihlâl yapan devletin üyelik haklarından bazılarının askıya alınması mümkündür. Bunun önkoşulu Avrupa Konseyi'nin, AB Parlamentosu'nun uygun görüşüne istinaden oybirliği ile AB anlaşmasının 2.maddesinde yer alan değerlerin ağır ve devam eden ihlâlini saptamasıdır ${ }^{42}$. Bununla beraber AB'nin, AB anlaşmasının 7.maddesinde öngörülen yaptırım prosedürü üzerinden üye devletlerdeki azınlıkların haklarına saygıyı temin etme potansiyeli oldukça sınırlı gözükmektedir. $\mathrm{Bu}$ durum herşeyden önce karmaşık prosedürden ve Konsey kararı için öngörülen oybirliği koşulundan ileri gelmektedir. Buna ilave olarak 7.maddeye sadece çok istisnai durumlarda -konu bağlamında ya azınlık haklarının açıkça ağır ihlâli tehlikesi içinde olması ya da bu ihlâlin sürekli olarak ortaya çıkmasıbaşvurabileceğinin gözardı edilmemesi gerekmektedir ${ }^{43}$. Lizbon sözleşmesi ile sütunlu yapının ortadan kaldırılması ve $A B$ Adalet Divanı'nın yarg1 yetkisinin $\mathrm{AB}$ anlaşmasının hükümlerine de teşmil edilmesi sonucu olarak $\mathrm{AB}$ anlaşmasının 2.maddesinde öngörülen değerlerden birinin ihlâli prensip olarak anlaşmalardan doğan yükümlülüklerin ihlâli gerekçesi ile Komisyonun AB'nin çalışma usulleri hakkındaki anlaşmanın 258.maddesine istinaden ihlâl davası açmasına yol açabilir ${ }^{44}$.

İnsan onuru, özgürlük yahut eşitlik kavramları yoruma açık olmaları nedeniyle çok sınırlı olarak yargı kararlarına esas alınabilirken, insan haklarının korunması bağlamında insan haklarının AB Temel Haklar Şartı ile primer hukukta (birincil hukukta) açık şekilde düzenlenmiş olması nedeniyle durum farklılık göstermektedir. Komisyon, Temel Haklar Şartı'nda yer alan bir hakkın ihlâlini davasına esas aldığı takdirde Temel Haklar Şartı'nın 51.madde, 1.fikrası muvacehesinde bu ihlâlin AB hukukunun icrası bağlamında ortaya çıktığını kanıtlaması gerekmektedir ${ }^{45}$. AB Komisyonu'nun üye devletlerde $\mathrm{AB}$ hukukunun icrası problemlerini de ele almayı düşündüğü y1llık raporlar $\mathrm{AB}$ değerlerine riayet bağlamında şimdiye dek üye devletlere uygulanan "Monitoring" mekanizmasının (denetim) daha fazla işletilmesine

\footnotetext{
42 Katharina SERINI, "Sanktionen der Europäischen Union bei Verstoß eines Mitgliedstaats gegen das Demokratie - oder Rechtsstaatsprinzip", Schriften zum Europäischen Recht, Vol.141, DunckerHumboldt, Berlin, 2009, s.121 vd., s.181 vd.

43 Katharina SERINI, s.136 vd.

44 Dietrich MURSWIEK, Die heimliche Entwicklung des Unionsvertrages zur europäischen Oberverfassung -zu den Konsequenzen der Auflösung der Säulenstruktur der europäischen Union und der Erstreckung der Gerichtsbarkeit des EU- Gerichtshofs auf den EU-Vertrag, NVwZ (Neue Zeitschrift für Verwaltungsrecht), Heft 8, 2009, s.481

45 EU, KOM (2010) 573 endg. 19.10.2010
} 
yol açabilir ${ }^{46}$. Avrupa Parlamentosu tarafından 2001'den itibaren AB'de insan hakları durumuna ilişkin düzenlenen raporlar önemli hususlara işaret etmekle beraber sistematik bir gözetim ve denetim mekanizması olarak mütalâa edilmemektedir ${ }^{47}$.

Aynı durum 2007'de kurulan AB Temel Haklar Ajans1 için geçerlidir. AB Temel Haklar Ajansı yetki alanlarında önlem almaları yahut tasarrufta bulunmaları bağlamında Birlik organlarına ve üye devletlere temel haklara saygılarını kolaylaştırmak için önemli bilgiler ve veriler toplamakta ve analiz etmektedir ${ }^{48}$. AB Temel Haklar Ajansı Tüzüğü'nün 10 nolu mülâhazası, AB Temel Haklar Ajansının faaliyetlerinin azınlık mensubu bireylerin haklarını kapsadığını öngörmektedir. Ajans aynı şekilde temel hak sorunları ve spesifik konular hakkında, bu meyanda AB'nde genel olarak azınlıların korunması konusunda raporlar hazırlamaktadır ${ }^{49}$. AB Temel Haklar Ajansı da üye devletlerdeki temel hak sorunlarını sadece Birlik hukukunun üye devletlerde icrası bağlamında ele alabilmektedir. Üye devletlerin $\mathrm{AB}$ anlaşmasının 2.maddesinde yer alan değerlere riayetine ilişkin kapsamlı bir gözetim yetkisi AB Temel Haklar Ajansına tanınmamıştır. Buna karşılık AB anlaşmasının 7.maddesi muvacehesinde uygulanan prosedür bağlamında $\mathrm{AB}$ organlarının AB Temel Haklar Ajansından danışma görüşü alması caiz kabul edilmektedir ${ }^{50}$.

\section{III - AB’ne Katılım Koşulu Olarak Azınlık Haklarının Korunması}

$\mathrm{AB}$ anlaşmasının 2.maddesinde öngörülen $\mathrm{AB}$ 'nin istinat ettiği değerler AB'nin genişlemesi bağlamında önem taşımaktadır. Ekonomik kriterler yanısıra belli anayasal temel esasların gereğinin yerine getirilmesi AB'ne katılımın maddi hukuk koşulu olarak kabul edilmektedir ${ }^{51}$. Azınlık hakları

$46 \mathrm{Bu}$ çerçevede hazırlanan ilk raporda üye devletlerdeki somut durumlara yer verilmemiştir. Krşt.:"'Bericht 2000 über die Anwendung der Charta der Grundrechte der Europäischen Union", SEK (2011) 396.endg., 30.03.2011

47 Bericht über die Lage der Grundrechte in der Europäischen Union (2009) -wirksame Umsetzung nach Inkrafttreten der Vertrags von Lissabon"; A7-0344/2010, 1.12.2010

48 AB Temel Haklar Ajansının kurulmasına ilişkin 168/2007 sayı ve tarihli tüzük için bknz.: AB1. L.53, 22.02.2007,1

49 Respect for and Protection of Persons Belonging to Minorities, 2008-2010, Report (2010), 23

50 Armin von BOGDANDY/Jochen von BERNSTORFF, "Die Europäische Agentur für Grundrechte in der europäischen Menschenrechtsarchitektur und ihre Fortentwicklung durch den Vertrag von Lissabon", Menschenrechte und Volkssouveränität in Europa, Gret HALLER et al. (ed), Campus Verlag, Frankfurt/New York, 2011, s.242

${ }^{51}$ Matthias HERDEGEN, "Europäische Union als Wertegemeinschaft: aktuelle Herausforde- 
korumasına atıf yapan $\mathrm{AB}$ anlaşmasının 2.maddesi içeriği itibariyle Avrupa Topluluklarına aidiyetin temel unsurlarını parlamenter demokrasiye ve insan haklarına sayg1 olarak belirleyen Avrupa Konseyi'nin Kopenhag kriterleri olarak bilinen 1993 tarihli AB'ne katılım kriterlerini belirleyen kararını aşmıştır ${ }^{52}$. Bu durum başlangıçtan itibaren-soft law karakterli olsa da- AB'ne katılım koşullarının gelişmeye devam ettiğini göstermektedir. Amsterdam anlaşmasının 1999 Mayıs'ında yürürlüğe girdiği tarihe kadar AB'ne katılımın yegâne koşulu "Avrupalı" olmak iken, AB anlaşmasının Amsterdam metninin 49.madde, 1.cümlesinde AB'nin anayasal değerlerine atıf yapılmıştır. AB'ne katılacak devletler söz konusu hükme göre sadece bu değerlere sayg1 göstermekle değil, aynı zamanda bu değerleri yerine getirmekle mükelleftir. AB anlaşmasının katılımla ilgili 49.maddesi, 4.cümlesinde anlaşmanın 2.maddesine yapılan atıf ve Avrupa Konseyi'nin kararlaştırdığ 1 kriterlerin tam üyelik başvurularında dikkate alınacağına ilişkin vurgu $A B$ organlarının da AB'nin genişlemesi bağlamında bu tür bir mükellefiyete tâbi olduğunu göstermektedir.

$\mathrm{Bu}$ tablo, AB'nin azınlı mensubu bireylerin hakları konusunda aday devletlerden beklentilerini ortaya koymaktadır ${ }^{53}$. Bu beklentilerin gerçekleşmesi 1990'lı yıllardan itibaren AB'de azınlık hakları bağlamında geliştirilen tüm araçların aday devletlerde azınlık haklarının koruması bağlamında kullanılmasına bağlıdır. AB'nin anlaşmaya dayanan ve otonom karakterli ilişkilerinde uygulanan koşulluluk prensibi nedeniyle ilgili proje ve önlemlerin $A B$ tarafindan mali olarak desteklenmesi katılım kriterlerine riayetin düzenli olarak Komisyonun ilerleme raporları ile takibi sonucu mümkün olmaktadır. Başlangıçta orta ve doğu Avrupa ülkeleri için geliştirilen bu uygulamanın bugün $\mathrm{AB}$ ile katılım ortaklığı ilişkisi olan veya $\mathrm{AB}$ 'ne potansiyel aday devletler için uygulandığ 1 görülmektedir.

IV - Birliğin Dış İlişkilerinde Azınlık Korumasının Yeri

$\mathrm{AB}$ 'nin dış ilişkilerinin $\mathrm{AB}$ anlaşmasının 49.maddesinde düzenlenen katılım prosedürü dışında Lizbon anlaşmasının yürürlüğe girmesinden itibaren

rungen", Wege gelebter Verfassung in Recht und Politik, Rainer PITSCHAS Arnd UHLE (ed.), Duncker\&Humboldt, Berlin, 2007, s.139 (s.141 vd.)

52 krşt.: Avrupa Konseyi’nin 08.04.1978 tarihli demokrasi açıklaması, Bull.EG 3-1978, 5

53 Christian PIPPAN, "Minderheitenschutz in den Außenbeziehungen der Europäischen Union und dessen Auswirkungen auf den Minderheitenschutz innerhalb der Union“, ETC European Training and Research Centre) Occasional Papers, No.18A, Graz, 2005, s.4 vd. 
$\mathrm{AB}$ primer hukukunda iki yerde düzenlendiği görülmektedir. $\mathrm{AB}$ anlaşmasının Birliğin ortak dış politikasının ve güvenlik politikasının detaylarının da düzenlendiği $\mathrm{V}$ nolu başlığında Birliğin dış ilişkileri bağlamında kimi temel hükümler öngörülmektedir. AB'nin çalışma usulleri hakkındaki anlaşmanın beşinci bölümü ise buna karşılık genel hüküm karakterli 205.madde yanısıra AB'nin dış ilişkiler alanında gelişmiş ülkelerle ortak dış ticaret politika, kalkınmada işbirliği, ekonomik, teknik mali işbirliği alanlarında operatif yetkilerini düzenlenmektedir. $\mathrm{AB}$ hukukunun hiçbir normu açık bir şekilde AB'ne uluslararası anlaşmalar yahut sekunder hukuk tasarrufları üzerinden üçüncü devletlerle azınlık haklarının korunması konusunda kooperasyon ilişkisi kurma yetkisi vermemektedir. Azınlıkların korunmasının ancak insan hakları korumasının bir kategorisi olması nedeniyle ${ }^{54}$ şimdiye dek geçerli hukuki durum azınlık haklarının AB'nin insan hakları (dış) politikasının bir boyutu olarak mütalâa edilmesini mümkün kılmıştır. Bugün geçerli $\mathrm{AB}$ primer hukuku bu durumu teyit etmekte ve güçlendirmektedir. AB'nin diş ilişkilerinde program norm rolü oynayan $\mathrm{AB}$ anlaşmasının 21.maddesi $\mathrm{AB}$ 'nin tüm dış ilişkilerinin öngörülen yetkiler dahilinde belli prensip ve amaçlara göre yürütülmesini düzenlemektedir. Anlaşmanın beşinci bölümünde düzenlenen uluslararası tasarrufların anlaşmanın 21.maddesinde yer alan prensiplere ve amaçlara göre yürütülmesi yükümlülüğünü $\mathrm{AB}$ 'nin çalışma usulleri hakkındaki anlaşmanın 205.maddesi teyit etmektedir. AB'nin çalışma usulleri hakkındaki anlaşmanın spesifik yetki normları da aynı formülasyonla Birliğe 3.devletlerle ve uluslararası örgütlerle ilişkilerini, Birliğin dış ilişkilerdeki prensipleri ve amaçları 1şığında şekillendirme ve icra etme yükümlülüğü getirmiştir. AB anlaşmasının 21.maddesi yakından incelendiğinde gerek genel hukuk ilkesi, gerekse normatif düzenleme olarak ortaya çıkan demokrasinin, hukuk devletinin ve insan haklarının yerleştirilmesinin ve geliştirilmesinin Birliğin dış ilişkilerinin somut hedefi olduğu ortaya çıkmaktadır ( $A B$ anl. md.21, fikra 1). Bunun ötesinde 21.madde, 2.fikra, a-bendine göre diş ilişkilerde AB değerlerinin korunması dikkate alınacak bir hedeftir.

\section{5 - Sonuç}

AB son yıllarda farklı seviyelerde ve farklı aksiyon alanlarında azınlıkların korunması ile iştigal etmiştir. Bu zaman zarfinda hernekadar $\mathrm{AB}$ azınlık hukukunun kimi esasları ortaya çıkmış ise de bunun henüz tam gerçekleşmediği, hattâ kimi bölümleri itibariyle tenakuzlu olduğu

${ }^{54}$ bknz.: Ulusal Azınlıklar Çerçeve Sözleşmesi md.1; yeni bir Avrupa için Paris Şartı, insani boyut bölümü 
görülmektedir ${ }^{55}$. Azınlık haklarının korunması AB'nin insan haklarının ve demokrasinin desteklenmesi politikaları bağlamında dış ilişkilerinde deklare ettiği bir hedeftir.

$\mathrm{AB}$ anlaşmasının temel değerlerle ilgili 2.maddesi ve ulusal azınlığa mensup olma nedeniyle ayrımcılık yapılamayacağını öngören 21.maddesi ve AB Temel Haklar Şartı'nın Lizbon sözleşmesi ile kazandığı primer hukuk hiyerarşisi AB'nin üçüncü devletlere karşı geliştirdiği söz konusu politikanın kendi alanında da azınlık haklarına güçlü bir şekilde saygı gösterilmesine yol açtığını göstermektedir. Anlaşmalarda açıklığa kavuşturulmayan AB'nin istinat ettiği bir değer olarak azınlıklara mensup bireylerin haklarının korunmasının somutlaştırılması bağlamında AB Temel Haklar Şartı'nın ve $\mathrm{AB}$ üyesi devletlerin akdine taraf olduğu yahut sonradan katıldığ konuyla ilgili uluslararası hukuk anlaşmalarının esas alınması mümkündür. $\mathrm{Bu}$ çerçevede gözden kaçırılmaması gereken bir husus da azınlık korumasının $\mathrm{AB}$ hukukunda eskiden olduğu gibi henüz status nascendi aşamasında bulunmasıdır. Wolfram Karl'ın bir süre önce Avrupa Konseyi ile bağlantılı yaptığ 1 yorum AB için de geçerlidir. Wolfram Karl'ın bu bağlamda Avrupa azınlık haklarını koruma bilançosunun bütünü itibariyle kötü gözükmediğine, bununla beraber demokrasi, insan hakları, hukuk devleti konusunda kendini özel olarak yükümlü kılan ve kültürel zenginlikleri nedeniyle gurur duyan bir örgütün, azınlıkların korunması konusunda çok daha fazla şeyler yapma olanağ1 bulunduğuna, bunun hattâ gerekli olduğuna ilişkin yapmış olduğu açıklamanın gözardı edilmemesi gerekmektedir.

\section{BIBLIYOGRAFYA:}

BIEBER,Roland/EPINEY,Astrid/HAAG,Marcel, Die Europäische Union, 9.bas1, Nomos Verlag 2011

BOGDANDY,Armin von./BERNSTORFF,Jochen von, "Die Europäische Agentur für Grundrechte in der europäischen Die Europäische Agentur für Grundrechte in der europäischen Menschenrechts-architektur und ihre Fortentwicklung durch den Vertrag von Lissabon", Menschenrechte und Volkssouveränität in Europa, Gret Haller et al. (ed.), Campus Verlag, Frankfurt/NewYork,2011

\footnotetext{
55 Peter HILPOLD, s.487
} 
CALLIESS,Christian, "Art.2 EUV", EUV/AEUV: Das Verfassungsrecht der Europäischen Union - Kommentar, Matthias Ruffert (ed.), 4.bas1, Beck Verlag, Münih/Frankfurt, 2011

HERDEGEN,Matthias, "Europäische Union als Wertegemeinschaft: aktuelle Heraus-forderungen", Wege gelebter Verfassung in Recht und Politik, Rainer Pitschas/Arnd Uhle (ed.), Duncker\&Humboldt, Berlin, 2007

HILPOLD, Peter, "Minderheiten im Recht der Europäischen Union", Zur Entstehung des modernen Minderheitenschutzes in Europa, Christoph Pan/Beate Sybille Pfeil (ed.), Springer Verlag, New York, 2006

HILPOLD,Peter, "Neue Minderheiten im Völkerrecht und im Europarecht", AVR, Bd.42, Say1 1, 2004

HOFFMEISTER,Frank, "Grundlagen und Vorgaben für den Schutz der Minderheiten im EU-Primärrecht", ZaöRV, Bd.68, 2008

HÖHN, Christiane, Zwischen Menschenrechten und Konfliktprävention: Der Minderheiten-schutz im Rahmen der Organisation für Sicherheit und Zusammenarbeit in Europa (OSZE), Springer Verlag, Berlin/Heidelberg, 2005

HÖLSCHEIDT, Sven, "Artikel 22: Vielfalt der Kulturen, Religionen und Sprachen”, Charta der Grundrechte der Europäischen Union, Jürgen Meyer (ed.), 3.bas1, Helbing \& Lichtenhahn Verlag, Basel, 2011

HUMMER, Waldemar, "Minderheitenschutz im Recht der EU vor und nach dem Inkrafttreten des Vertrages von Lissabon - vom bloßen Diskriminierungsverbot zu 'affirmative actions", EJM, No.2, 2011

KARL,Wolfram, "Der Schutz der Minderheitenrechte im Rahmen des Europarats", Schutz und Durchsetzung der Rechte nationaler Minderheiten, Gerhard Hafner/Martin Pandel (ed.), Nomos, BadenBaden, 2008

KLEIN,Eckart, "Das Verhältnis des EuGH zum EGMR", Handbuch der Grundrechte VI/1: Europäische Grundrechte I, Detlef Merten/Hans Jürgen.Papier (ed.), Mohr Siebeck, Heidelberg, 2010

MURSWIEK, Dietrich, Die heimliche Entwicklung des Unionsvertrages zur europäischen Oberverfassung -zu den Konsequenzen der Auflösung der Säulenstruktur der europäischen Union und der Erstreckung der Gerichtsbarkeit des EU- Gerichtshofs auf den EU- 
Vertrag, NVwZ Heft 8, 2009

OPITZ,Maximillian, Die Minderheitenpolitik der Europäischen Union, Lit Verlag, Münster, 2007

PALERMO,Francesco, "Annäherungen and den Verfassungsrecht der Europäischen Verfassungsraums", Vom Verfassungsstaat am Scheideweg, Karl Weber/Norbert Wimmer (ed.), Springer, Vienna/New York, 2005

PIPPAN,Christian "Minderheitenschutz in den Außenbeziehungen der Europäischen Union und dessen Auswirkungen auf den Minderheitenschutz innerhalb der Union", ETC Occasional Papers, No.18A, Graz, 2005

SCHORKOPF,Frank "Homogenität in der Europäischen Union Ausgestaltung und Gewährleistung durch Art.6, Abs.1 und Art.7 EUV”, Hamburger Studien zum Europäischen und Internationalen Recht, Bd. 21, Duncker \& Humblot, Berlin, 2000

SCHUTTER, Oliver de Die Anerkennung der Rechte von Minderheiten und die Gleich-behandlungsagenda der EU, Europäische Zeitschrift zum Anti-diskriminierungsrecht, \#11, Dec. 2010, s.25

SERINI,Katharina "Sanktionen der Europäischen Union bei Verstoß eines Mitgliedstaats gegen das Demokratie - oder Rechtsstaatsprinzip", Schriften zum Europäischen Recht, Vol.141, Duncker\& Humboldt, Berlin, 2009

SHORAKA,Kirsten Human Rights and Minority Rights in the European Union, Taylor and Francis Group, London/New York, 2000

ROSSI,Matthias “Art.352 AEUV”, EUV/AEUV: Das Verfassungsrecht der Europäischen Union - Kommentar, Christian Calliess/Manfred Ruffert (ed.), 4.bas1, C.H.Beck Verlag, Münih/Frankfurt, 2011

RUFFERT,Manfred, “Art.7 EUV”, EUV/AEUV: Das Verfassungsgericht der Europäischen Union - Kommentar, Christian Calliess/Manfred Ruffert (ed.), 4.bas1, C.H.Beck Verlag, Münih/Frankfurt, 2011

WENZEL,Nicola, Das Spannungsverhältnis zwischen Gruppenschutz und Individualschutz im Völkerrecht, Springer Verlag, Berlin/ Heidelberg/ New York, 2008

WINKLER,Roland, Die Grundrechte der Europäischen Union, Springer Verlag, Wien/New York, 2006 